Editorial

\title{
Magnetochemistry: From Fundamentals to Applications
}

\author{
Carlos J. Gómez-García \\ Instituto de Ciencia Molecular (ICMol), Universidad de Valencia, C/Catedrático José Beltrán, 2, \\ 46980 Paterna, Valencia, Spain; carlos.gomez@uv.es
}

Received: 20 January 2016; Accepted: 21 January 2016; Published: 25 January 2016

It is well knowm that Magnetochemistry is a multidisplinary area that deals with many different materials and properties. The first issue of the new journal Magnetochemistry clearly confirms this fact. Thus, in this first issue we can read five different contributions with very different subjects as the magnetic properties of $\mathrm{Pt}_{13}$ nanoclusters with superatom character, new $\mathrm{V}_{4}$ and $\mathrm{V}_{6}$ complexes with $\beta$-diketone ligands presenting novel topologies, a theoretical study of the magnetic coupling of transition metal complexes through functionalized chiral and C60-filled bridging carbon nanotubes, the first spin crossover transition in a Mn(II) chain and a study of the effect of the size and electronic configuration on the magnetic coupling in lantanide-copper complexes.

Thus, in the first article [1], Roduner and Jensen show the synthesis of nearly spherical $\mathrm{Pt}_{13}$ nanoclusters in the pores of $\mathrm{NaY}$ and KL zeolites presenting high spin states, blocking temperatures and superdiamagnetic properties strongly dependent on the amount of chemisorbed $\mathrm{H}_{2}$. These properties are rationalized assuming that the $\mathrm{Pt}_{13}$ nanoparticles behave as analogues of transition metal atoms (superatoms) with high and low spin states and molecular orbitals delocalized in the cluster.

In the second article [2], G. Aromí et al. explore the chemistry of vanadyl ions $\left(\mathrm{VO}^{2+}\right)$ with bis- $\beta$-diketone ligands and pyridine. With this strategy they prepare a novel $\mathrm{V}^{\mathrm{IV}}$ tetranuclear complex and a mixed valence hexanuclear $\mathrm{V}_{4} \mathrm{~V}^{\mathrm{IV}}{ }_{2}$ complex, both presenting novel topologies thanks to the conformation flexibility of the bis- $\beta$-diketone ligands. The magnetic properties of these complexes reveal the presence of $S=2$ and $S=1$ ground spin states.

In the third article [3], Ruiz and Gómez-Coca show a theoretical DFT study of the magnetic coupling of transition metal complexes connected through chiral and filled carbon nanotubes (CNT) since these nanotubes present highly delocalized $\pi$-electrons. This theoretical study shows that $\mathrm{Fe}(\mathrm{III})$ paramagnetic centres coordinated to terminal carboxylates groups in functionalized CNT present ferro or antiferromagnetic coupling depending on the presence or absence of chirality in the CNT. This study also shows that the insertion of $\mathrm{C}_{60}$ inside the CNT (peapod structures) results in some cases in dramatic changes in the magnetic coupling.

In the fourth article [4], S. Benmansour et al. describe the synthesis and characterization of two novel magnetic coordination polymers with segregated cationic and anionic chains. One of these two compounds represents one of the very few known examples of $\mathrm{Mn}$ (II) complex with low spin configuration and the first low spin Mn(II) chain. Since this compound presents a partial spin crossover transition, it is the first $\mathrm{Mn}$ (II) chain presenting a SCO transition.

Finally, in the fifth article [5], Ghosh et al. describe a series of $\mathrm{Ln}_{2} \mathrm{Cu}$ trimers ( $\mathrm{Ln}=\mathrm{Ce}, \mathrm{Gd}, \mathrm{Tb}, \mathrm{Dy}$ and Er) where the size and electronic configuration of the $\operatorname{Ln}(\mathrm{III})$ ion play a key role in determining on one side the coordination geometry and, on the other side, the magnitude and sign of the magnetic coupling. This series represents the second reported one where the $\mathrm{Ln}-\mathrm{Cu}$ magnetic coupling through double oxyde bridges has been determined and confirms the hypothesis that the ferromagnetic coupling becomes stronger as the number of unpaired $\mathrm{f}$ electrons increases. 
From these examples, it is clear that the new journal Magnetochemistry is multidisciplinary and may be of interest for a plethora of researchers working in many different areas either from the theoretical or experimental points of view.

\section{References}

1. Roduner, E.; Jensen, C. Magnetic Properties and the Superatom Character of 13-Atom Platinum Nanoclusters. Magnetochemistry 2015, 1, 28-44. [CrossRef]

2. Borilovic, I.; Roubeau, O.; Fernández Vidal, I.; Teat, S.J.; Aromí, G. Novel Topologies in Vanadium-Bis-B-Diketone Chemistry: A [V4] and a [V6] Metallacyclophane. Magnetochemistry 2015, 1, 45-61. [CrossRef]

3. Gómez-Coca, S.; Ruiz, E. Magnetic Behaviour of Transition Metal Complexes with Functionalized Chiral and C60-Filled Nanotubes as Bridging Ligands: A Theoretical Study. Magnetochemistry 2015, 1, 62-71. [CrossRef]

4. Benmansour, S.; Triki, S.; Gómez-García, C.J. A Spin Crossover Transition in a Mn(II) Chain Compound. Magnetochemistry 2016, 2, 1. [CrossRef]

5. Ghosh, S.; Gómez-García, C.J.; Clemente-Juan, J.M.; Ghosh, A. Key Role of Size and Electronic Configuration on the Sign and Strength of the Magnetic Coupling in a Series of $\mathrm{Cu}_{2} \mathrm{Ln}$ Trimers $(\mathrm{Ln}=\mathrm{Ce}, \mathrm{Gd}, \mathrm{Tb}$, Dy and Er). Magnetochemistry 2016, 2, 2. [CrossRef]

(C) 2016 by the author; licensee MDPI, Basel, Switzerland. This article is an open access article distributed under the terms and conditions of the Creative Commons by Attribution (CC-BY) license (http://creativecommons.org/licenses/by/4.0/). 